\title{
Retrospectiva de los primeros sistemas de gráficos por ordenador
}

\begin{abstract}
Resumen
La trayectoria histórica que gira alrededor de los sistemas gráficos por ordenador abarca momentos cruciales que, desde las primeras representaciones registradas, nos ha permitido conocer a los protagonistas más distintivos en el desarrollo de los sistemas gráficos por ordenador o los primeros comienzos del software como herramienta para el dibujo en formato digital. En este artículo, se resumen algunas de las más relevantes aportaciones seleccionadas minuciosamente y que nos presentan una visión histórica desde los años 50 hasta finales de los 70 del constante cambio y el acelerado crecimiento de los medios que actualmente ofrecen otro enfoque para la creación gráfica mediante los sistemas digitales.
\end{abstract}

Esta aportación nos introduce a conocer los orígenes del software gráfico que ha cambiado la técnica de producción para muchos creativos del diseño y la ilustración y hemos querido hacer un guiño a todos aquellos que, gracias a su curiosidad, inquietud e investigación, nos han legado nuevos medios para la expresión gráfica.

Palabras clave: dibujo vectorial, software gráfico, historia, diseño.

\section{Retrospective of the first systems and computer graphics programs}

\section{Abstract}

The historical trajectory that revolves around computer graphic systems covers a crucial moment that, from the first performances recorded, has revealed the most distinctive leaders in the development of computer graphic systems or the first beginnings of the software as a tool for drawing in digital format. In this article are summarized some of the most important contributions, selected carefully, and they present us a historical overview from the 50s to late 70s, of the constant change and the rapid growth of the means that currently offered another approach to graphic creation using digital systems.

This contribution introduces us to know the origins of graphic software that has changed the production technique for many designers and illustration creatives and we would wanted to make a nod to all those who, thanks to his curiosity, restlessness and research, has bequeathed us new means for graphic expression.

Keywords: vector drawing, graphic software, history, design.

Desde el comienzo del uso de los ordenadores a mediados de los años 40 hasta aproximadamente los 80 , se han ido utilizando sistemas de representación muy diferentes para la creación de gráficos por ordenador, las primeras visualizaciones se hacían en monitores vectoriales que mostraban la construcción de líneas y curvas producidas mediante un haz de electrones que marcaban el punto de origen y de destino de cada trazo. Por entonces, los rayos catódicos de estos monitores CRT 
(Cathode Ray Tube) mostraban canales de luz que repetían a gran velocidad las formas o segmentos para evitar las intermitencias visuales quedando en negro el resto de la pantalla. Esto permitía que las imágenes se apreciaran de una manera estática e incluso en movimiento, similar a la de los osciloscopios y con una resolución bastante aceptable para la época sin necesidad de grandes cantidades de memoria. Sin embargo, este tipo de monitores no eran capaces de mostrar más de un color (habitualmente verde o naranja), no podían representar relleno en las formas, solamente los contornos, y los textos debían ser cortos, cada carácter era dibujado individualmente a gran escala para poder apreciarlo.

Uno de los primeros sistemas gráficos fue el SAGE (Semi Automatic Ground Environtment) que se desarrolló en 1955 en el Lincoln Laboratory del MIT (Instituto de Tecnología de Massachussetts) para las Fuerzas Aéreas de los Estados Unidos, procesando datos de radar y localizaciones de objetos con el equipo TX-0, el primer ordenador transistorizado que llevaba incorporado un programa residente además de un osciloscopio.

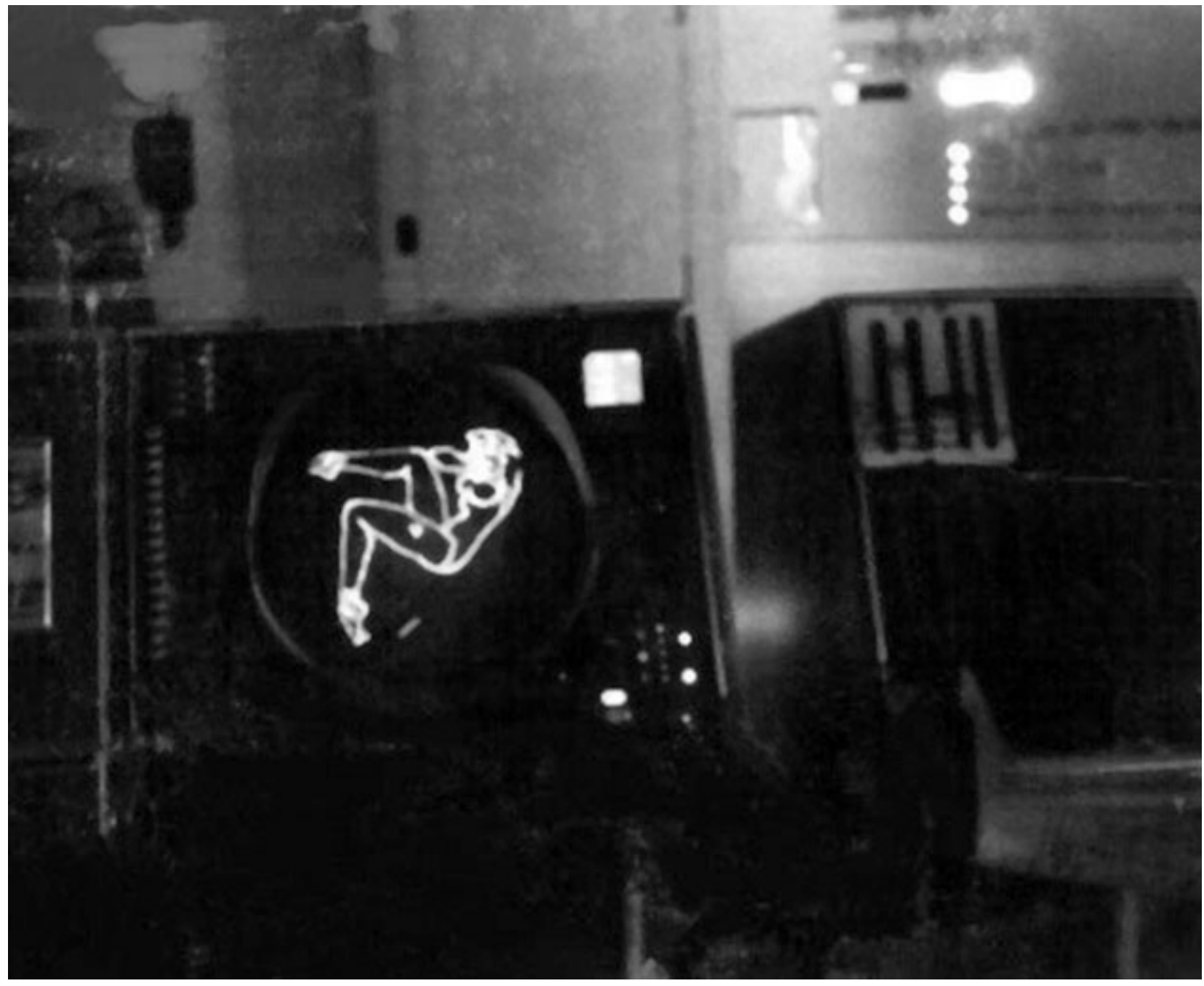

Fig. 1. Primera imagen figurativa digital, recreación de chica Pin-Up a finales de los años 50.

Como curiosidad para la historia de la ilustración gráfica por ordenador, queremos hacer mención a un artículo de Benj Edwards en la revista The Atlantic ${ }^{1}$. En su entrevista con el veterano aviador Lawrence Tipton, donde cuenta la historia desde un punto subjetivo de lo que muchos ya consideran como el primer gráfico figurativo realizado con ordenador. Se trata de la silueta de una 
chica Pin-Up inspirada en una ilustración impresa de George Petty (1894-1975) para el calendario de la revista Esquire en 1956. Esta digitalización anónima se realizó con un costoso ordenador militar basado en el sistema de gráficos SAGE, el AN/FSQ-7, desarrollado por IBM y Las Fuerzas Aéreas de los Estados Unidos a finales de los años 50. Se trataba de una ilustración clandestina realizada bajo un lenguaje de programación que permitía dibujar líneas cortas o vectores y con la que consiguieron plasmar una forma figurativa humana, una programación que hasta entonces solo utilizaban para diagnosticar las transferencias de los datos de vuelos militares, pero en este caso aprovechada para otros fines más particulares.

El uso de estas máquinas creadas exclusivamente para fines militares también se perturbó cuando en 1952 se diseñó el primer juego gráfico por ordenador de la historia con el nombre de OXO, resultado de la tesis doctoral de Alexander Sandy Douglas (1921-2010) por la Universidad de Cambridge. Con este juego se pudo demostrar la interactividad entre el ser humano y los ordenadores creando una original versión del conocido juego tres en raya y programado con un equipo EDSAC (Electronic Delay Storage Automatic Calculator).

Entre su invención a mitad de los años cuarenta y la llegada de los PC a principios de los ochenta, el ordenador digital se usó de forma prácticamente exclusiva para realizar cálculos militares, científicos y empresariales o procesar datos. No era interactivo. No estaba diseñado para que lo utilizara una única persona. En resumen, no era apto para la creación cultural ${ }^{3}$.

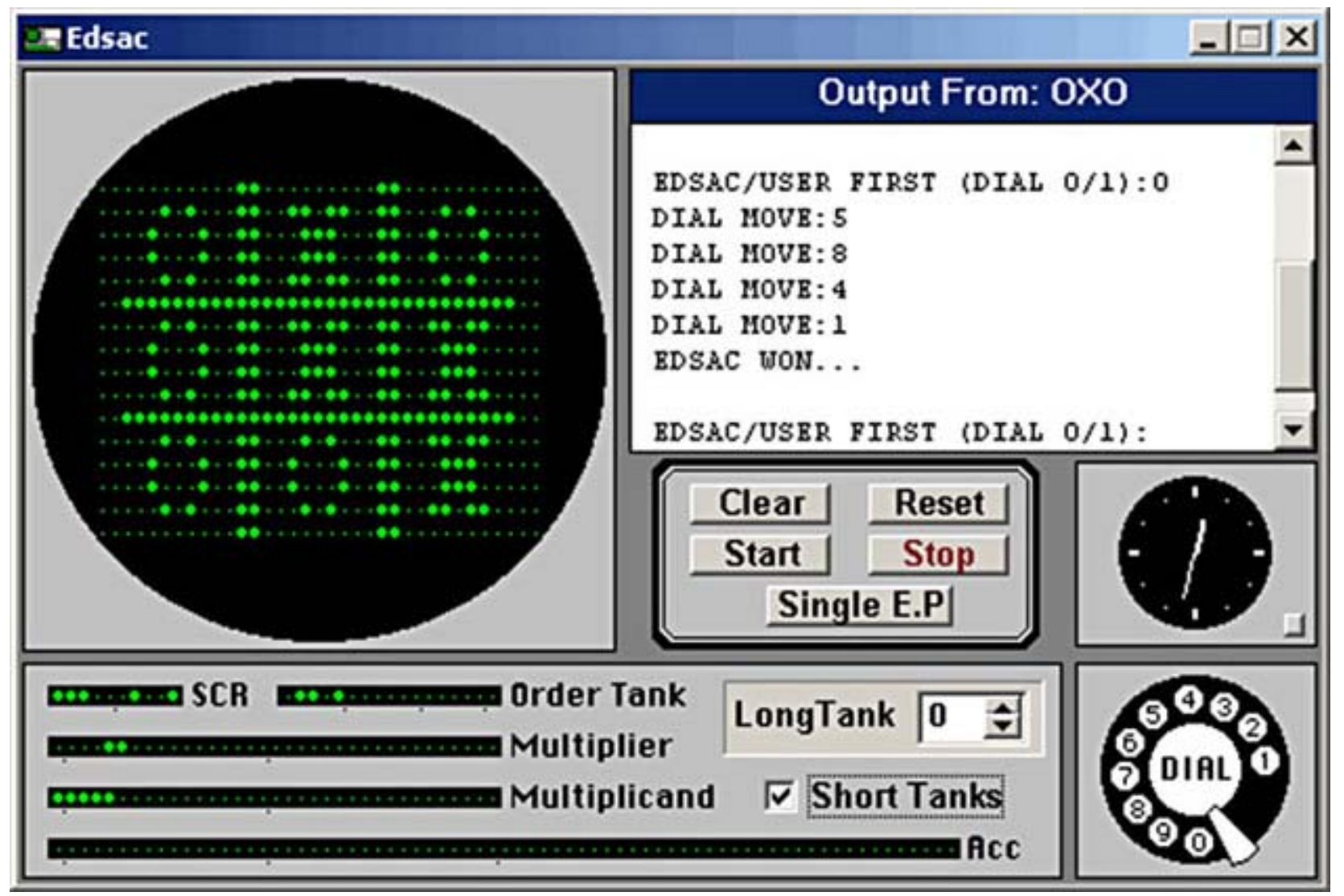

Fig. 2. Simulador del juego OXO (tres en raya). El jugador hace su entrada mediante un dial telefónico de rueda y la salida visual se mostraba en una pantalla de tubo de rayos catódicos. 


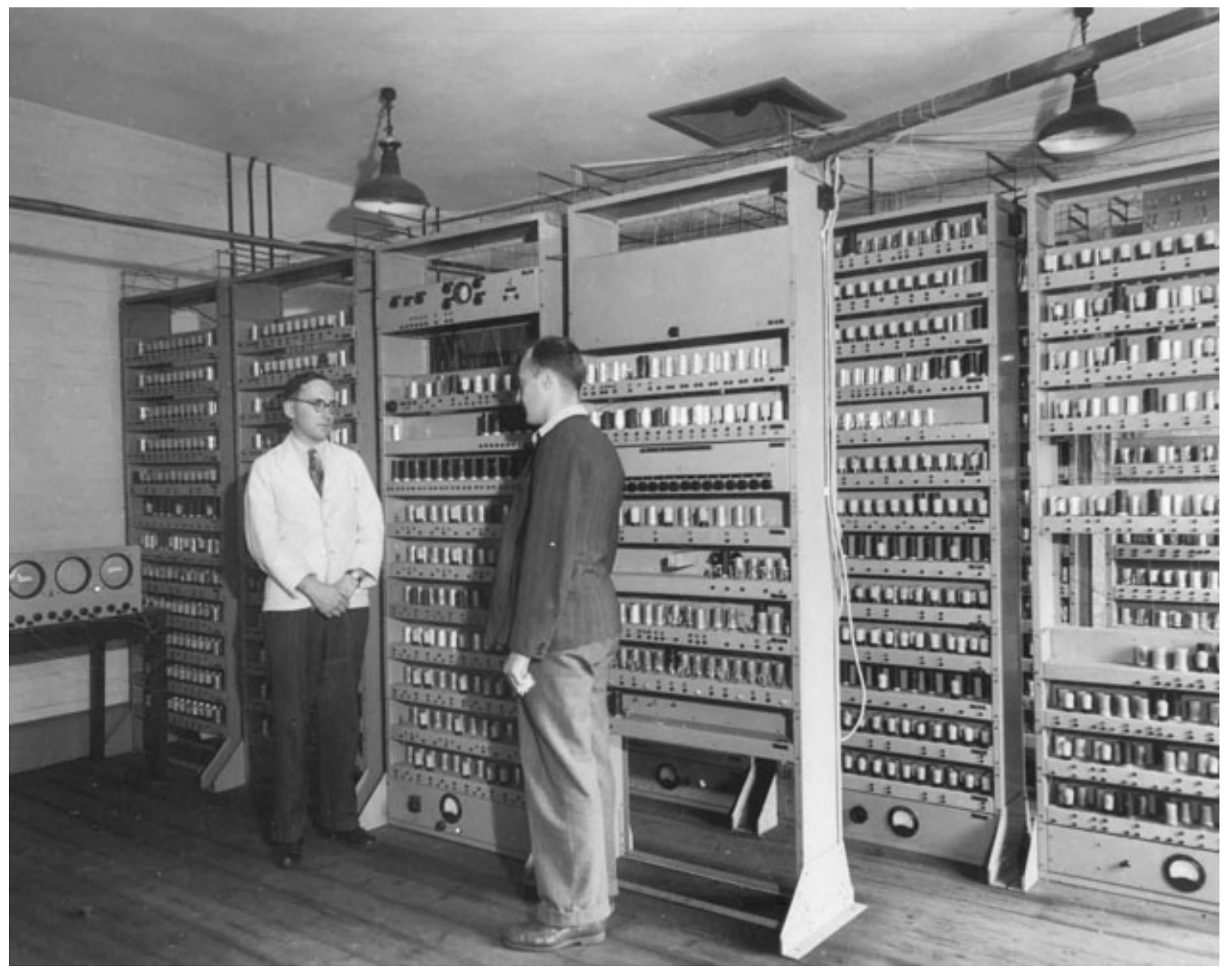

Fig. 3. La EDSAC, desarrollada por Maurice Wilkes en la Universidad de Cambridge. Sus primeras aplicaciones se diseñaron en 1949 y se convirtió en el primer ordenador con un programa interno de almacenamiento digital para hacer de uso regular. Foto de archivo de la Universidad de Cambridge.

En 1958, William Higinbotham (1910-1994), físico que participó en un innovador sistema de radar y que desgraciadamente más tarde utilizarían en la Segunda Guerra Mundial con el avión Enola Gay y su destructiva bomba nuclear. Cuando Higinbotham era director de la División de Instrumentación del Laboratorio Nacional Brookhaven en la década de los cincuenta, consiguió crear algo diferente y entretenido, adaptando sus conocimientos tecnológicos sobre el radar. Diseñó una aplicación para el ocio, el Tennis for two ${ }^{4}$, el primer video juego electrónico basado en un programa de cálculo de trayectorias que el ejército americano utilizaba por aquella época y con el que al menos consiguió amenizar los duros tiempos de guerra entre los compañeros de la división y sus visitas.

El diseño del juego de Higinbotham terminó siendo demasiado costoso ya que su finalidad era solo para uso de entretenimiento, así que concluyó pronto su propósito siendo su máquina desarmada y sentenciando las piezas para otros menesteres. Higinbotham pasó a la historia sin apenas reconocimiento ya que nunca patentó su invento.

Todos los resultados gráficos que realizaban estas grandes máquinas eran de uso exclusivamente militar, consiguieron que, gracias a las mentes inteligentes y curiosas de estos hombres (quizás por huir un instante de la cruda realidad que les tocaba vivir), fueran precursores de una sutil ilustración gráfica realizada por ordenador y de los actuales videojuegos. 


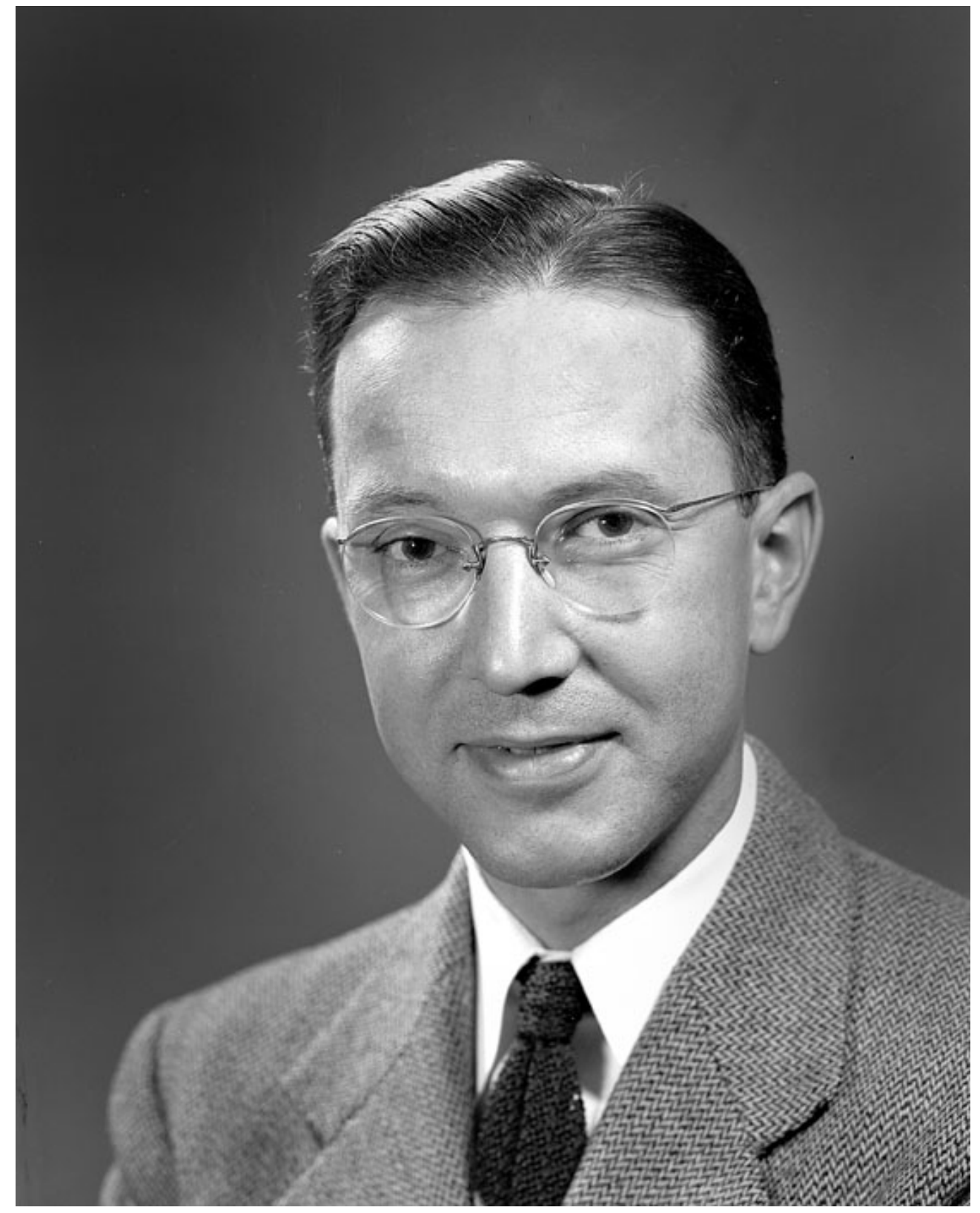

Fig. 4. William Higinbotham, creador del primer videojuego, el Tennis for two.

Fue en 1963 cuando Ivan Sutherland (1938), profesor, informático y para muchos considerado como uno de los pioneros de Internet y de la creación de gráficos por ordenador; hacía realidad uno de los proyectos más ambiciosos y con más repercusión en la historia de la ingeniería moderna: "Crear una interfaz gráfica para diseñar objetos en un ordenador", tema sobre el que trabajó en su tesis doctoral en el MIT "SketchPad: A man-machine graphical communication system" ${ }^{\text {"5 }}$. Sutherland fue pionero en la búsqueda de una solución para representar gráficos digitalmente y que con un equipo TX-2 creó uno de los primeros programas de diseño asistido por ordenador (CAD). Hablamos del Sketchpad, que aunque hoy en día consideremos un sistema bastante rudimentario, también atiende al origen de las pantallas táctiles actuales, ya que utilizaba un lápiz óptico, inventado un año atrás. Presionando con este lápiz sobre la pantalla y ayudado de una serie de interruptores, permitía introducir formas lineales en el ordenador, dando así comienzo al primer sistema electrónico programado para el dibujo de gráficos. 


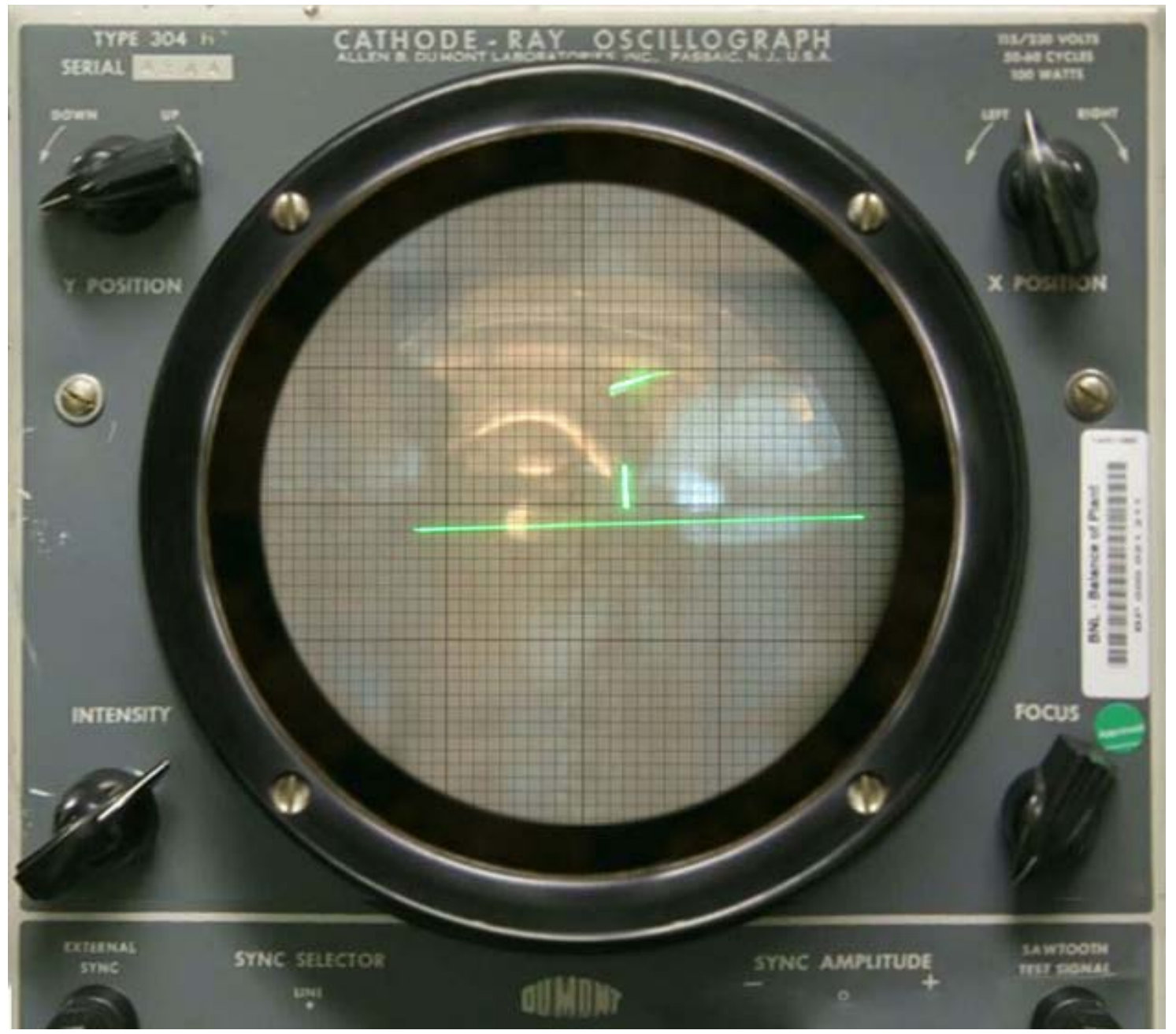

Fig. 5. Recreación del videojuego original Tennis for two, construido para el 50 aniversario de su aparición.

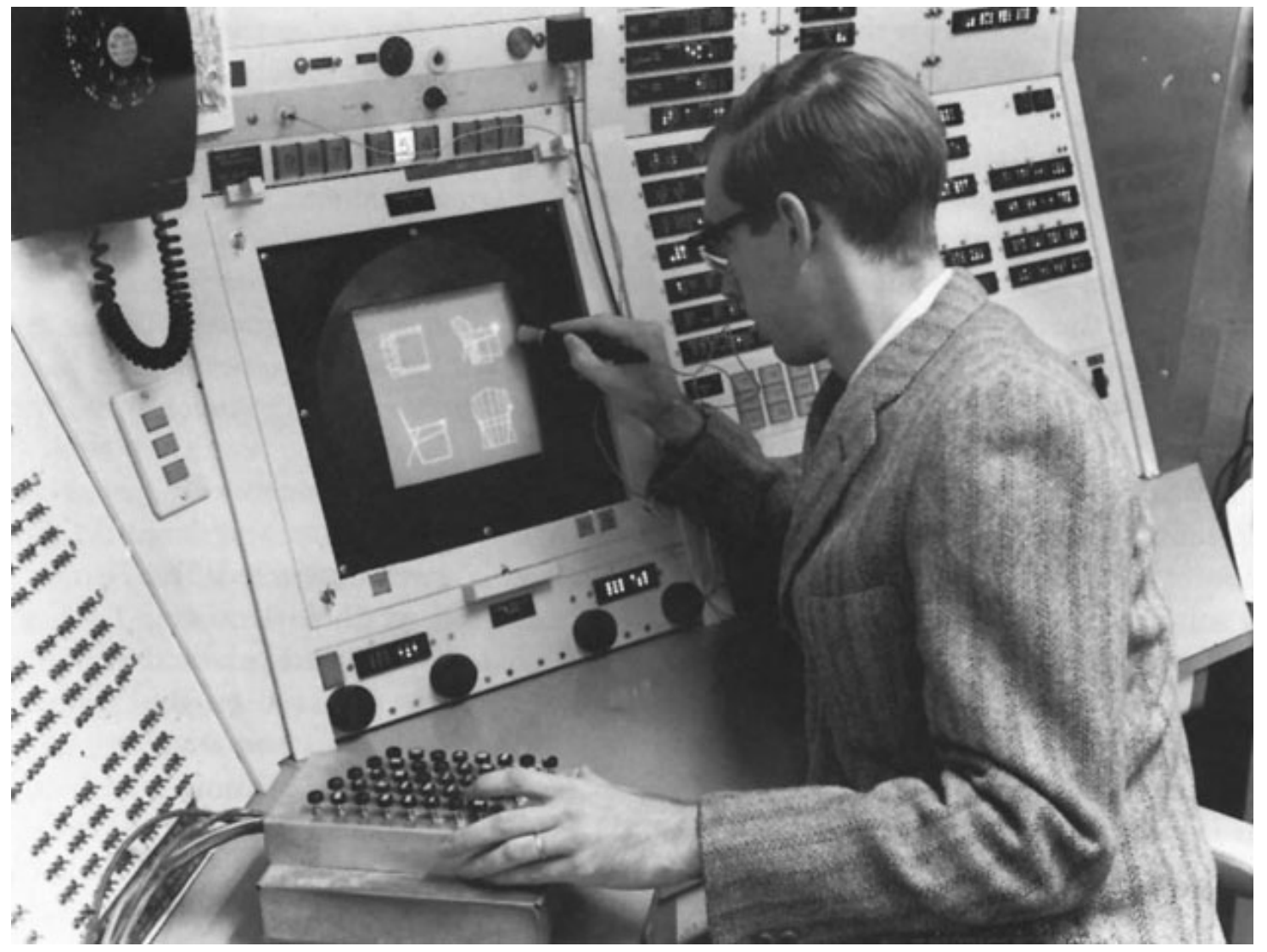

Fig. 6. Ivan Sutherland ante un equipo TX-2 utilizando el lápiz óptico en el Sketchpad. 1963. 
Como comentaba Sutherland en la introducción a su tesis, el Sketchpad es un sistema que permite a los usuarios dibujar puntos, segmentos de líneas y arcos circulares, directamente en la pantalla mediante un lápiz de luz. Estos elementos se podían mover, redimensionar, borrar y modificar.

A Sketchpad user sketches directly on a computer display with a light pen. The light pen is used both to position parts of the drawing on the display and to point to them to change them. A set of push buttons controls the changes to be made such as "erase" or "move". Except for legends, no written language is used.

Information sketched can include straight line segments and circle arcs. Arbitrary symbols may be defined from any collection of line segments, circle, arcs, and previously defined symbols. A user may define and use as many symbols as he wishes. Any change in the definition of a symbol is at once seen wherever that symbol appears ${ }^{6}$.
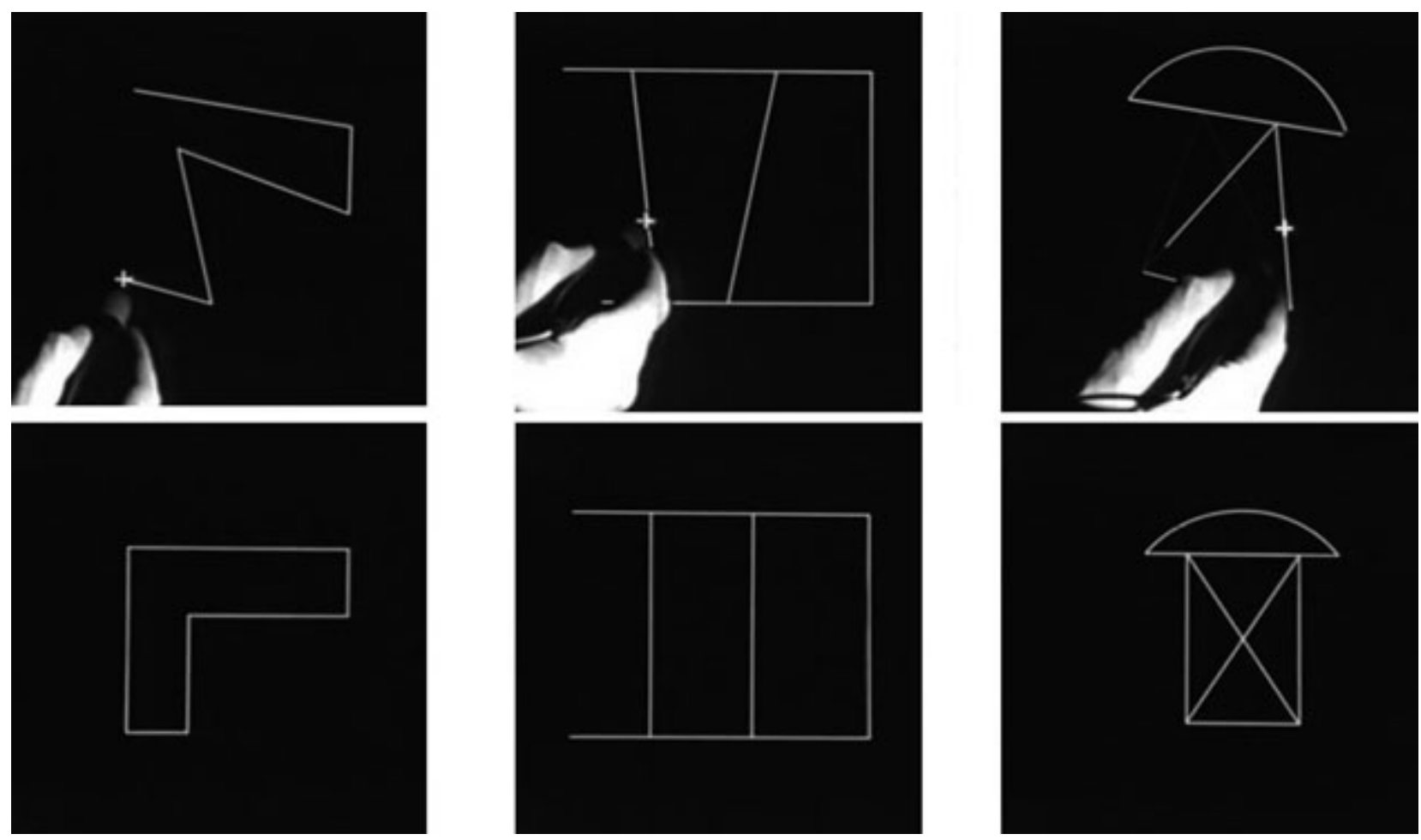

Fig. 7. Fotogramas del video de demostración del Sketchpad que ilustran el uso de las restricciones en el programa. Fila superior: El usuario selecciona partes de un dibujo. Fila inferior: Sketchpad ajusta los dibujos automáticamente.

Este sistema fue utilizado solamente por algunas compañías de aviación y automoción en la década de los 60 debido al alto coste de la maquinaria que lo manejaba. Sin embargo, su trabajo ayudó a constituir una de las primeras bases del desarrollo de la interfaz gráfica de usuario tal y como la conocemos hoy en día al introducir conceptos como la interactividad, el modelado de formas bidimensionales y el modelado orientado a objetos tridimensionales facilitando el trabajo visual más allá de los números y el lenguaje de programación, poniendo base a la informática moderna, pasando del mundo exclusivamente académico de investigación a una funcionalidad para el uso comercial y profesional.

En 1964, inspirado en el trabajo de Ivan Sutherland, el ingeniero e inventor Douglas Engelbart (1925-2013) que, junto a su colega Bill English, realizó en el Stanford Research Institute el primer 
prototipo de un nuevo dispositivo para "apuntar" a los objetos en una pantalla de una manera bastante más efectiva que el lápiz de luz en las pantallas CRT, hablamos del mouse ${ }^{7}$ o ratón. En 1968, Engelbart lo presentó ${ }^{8}$ oficialmente y este invento vaticinó un gran cambio para la informática moderna y por supuesto para el dibujo por ordenador. La primera empresa que adquirió, tomó la idea de este artilugio y lo comercializó en el primer ordenador con un ratón incluido fue Apple, con el equipo modelo Xerox Star 8010, lanzado al mercado a nivel usuario en 1981.

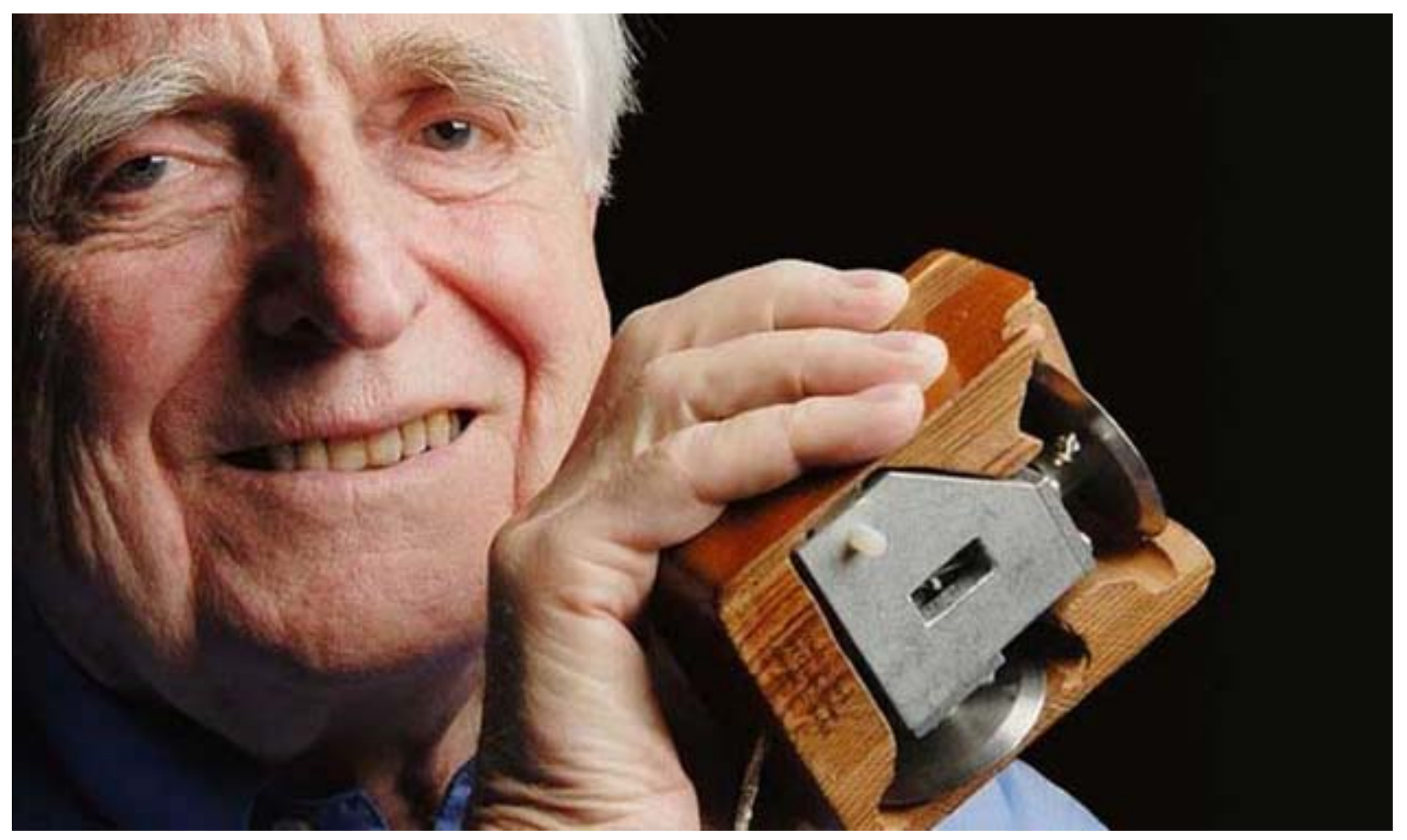

Fig. 8. Mouse diseñado por Dougles Engelbart. El primer prototipo se construyó de manera artesanal. Estaba construido de madera y se patentó con el nombre "X-Y Position Indicator for a Display System". Fotografía: Robert Holmgren.

Entre los años 70 y 80 Alan Kay (1940), informático estadounidense, pionero en el diseño de la Interfaz Gráfica de Usuario (GUI), trabajaba para la Xerox PARC (Palo Alto Research Center), una empresa de investigación y desarrollo con sede en Palo Alto (California) y creada por la Xerox Corporation en 1970. Gracias al grado de libertad del que disponían los investigadores en esta compañía, podían experimentar casi sin restricciones con todo tipo de conceptos y se pusieron como objetivo proporcionar a las empresas un entorno de trabajo que permitiera desarrollar nuevas tecnologías para que se pudieran convertir en productos comerciales. De la Xerox PARC surgieron casi todos los componentes principales que dieron origen a los PC actuales y así nació la estación de trabajo Xerox Alto, un ordenador revolucionario que empleaba una interfaz basada en mapa de bits en vez de una terminal de texto. Cuando hablamos de las GUI (Interfaz Gráfica de Usuario) hablamos del conjunto de métodos y formas que permiten la interacción de un ordenador con los usuarios utilizando formas gráficas como botones, iconos, ventanas, etc. dando como resultados una información, una acción o aplicar unas funciones concretas, proporcionando un entorno visual sencillo e intuitivo. 
En el contexto del proceso de interacción persona-ordenador, la interfaz gráfica de usuario es el artefacto tecnológico de un sistema interactivo que posibilita, a través del uso y la representación del lenguaje visual, una interacción amigable con un sistema informático .

A partir de los años setenta, todos estos cambios de lenguajes, técnicas y conceptos se fueron informatizando dando lugar a una progresiva transformación social y cultural que han ido sustituyendo y evolucionando la mayor parte de las tecnologías aparecidas en los siglos XIX y XX. El software reemplazó muchas otras herramientas y tecnologías para los profesionales de la creación y en este aspecto, Alan Kay junto a otros compañeros de la Xerox PARC como Adele Goldberg $^{10}$ (1945), se convirtieron en los padres de la programación orientada a objetos mediante un tipo de lenguaje de programación llamado Smaltalk ${ }^{11}$ que fue el que se utilizó para diseñar la estación de trabajo Xerox Alto. Como curiosidad, el "Alto" ya disponía de un programa de dibujo vectorial llamado SIL y otro para gráficos en mapa de bits llamado Markup.

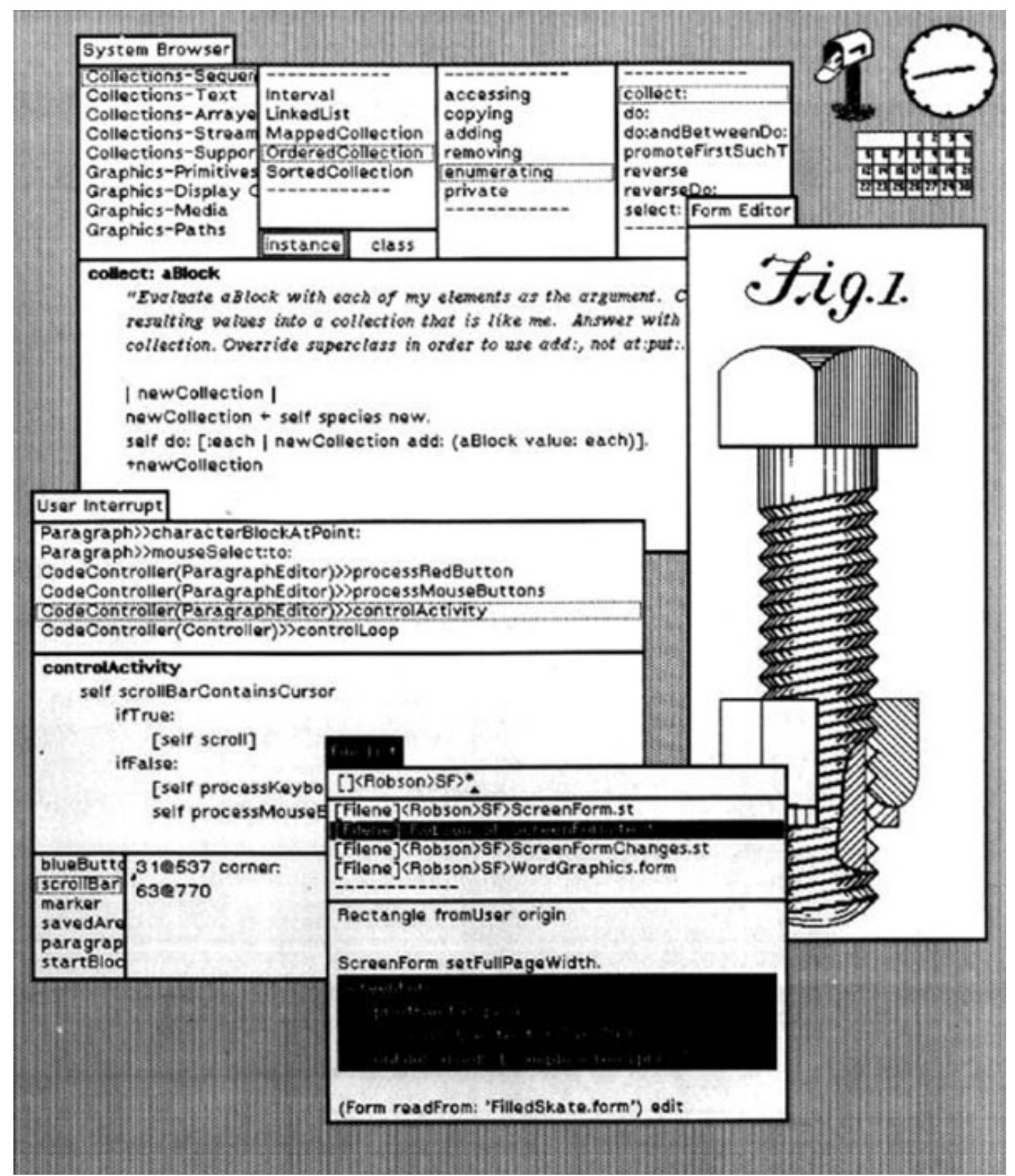

Fig. 9. Sistema de ventanas creadas mediante el lenguaje Smalltalk-80 para el ordenador Xerox Alto (1973). 
El propósito del proyecto Smalltalk es proporcionar soporte informático para el espíritu creativo en todo el mundo. Nuestro trabajo se deriva de una visión que incluye un individuo creativo y el mejor hardware de computación disponible. Hemos optado por concentrarlas en dos áreas principales de investigación: un lenguaje de descripción (lenguaje de programación) que sirve de interfaz entre los modelos de la mente humana y los de hardware de computación, y un lenguaje de la interacción (interfaz de usuario) que coincide con el sistema de comunicación humana a la de la computadora ${ }^{12}$.

Alan Kay también trabajó con Ivan Sutherland en aplicaciones gráficas pioneras, incluida el Sketchpad, pero sobre todo creó el concepto del Dynabook, un ordenador para niños de todas las edades, base de los ordenadores portátiles actuales.

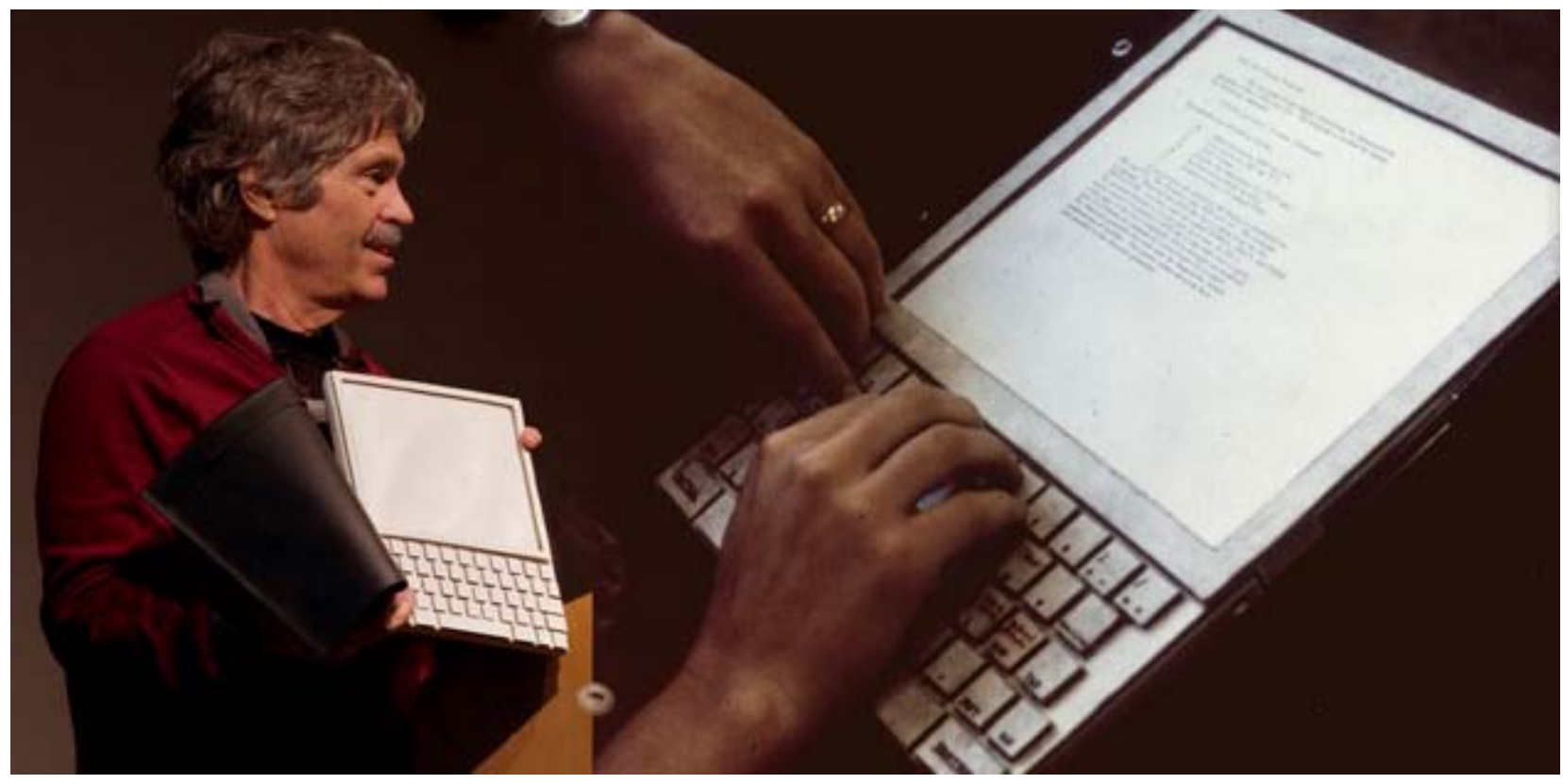

Fig. 10. Presentación del prototipo del Dynabook, concepto creado por Alan Kay en 1968.

Sobre el Dynabook, Kay y Goldberg, la visión del Learning Research Group del PARC era "cristalizar sus sueños sobre una idea de diseño para un medio dinámico personal del tamaño de un cuaderno, el Dynabook, para "que todo el mundo pueda adquirir y tenga la potencia para dar la respuesta a su propietario prácticamente de todas las necesidades relacionadas con la información"13. Estamos hablando de una condición visionaria de estos científicos hacia nuestro presente tecnológico mediante nuevos medios portátiles, interactivos y al alcance de todos donde planteaban si cada dispositivo "tuviera suficiente potencia para superar su sentido visual y auditivo, suficiente capacidad para almacenar el equivalente a miles de páginas de materiales de consulta, poemas, cartas, recetas, álbumes musicales, dibujos, animaciones, bandas sonoras, formas de onda, simulaciones dinámicas y cualquier otra cosa que desee recordar y cambiar, que le fueran accesibles en aquel momento"14.

A raíz de los setenta, los medios fueron cambiando todos los lenguajes, técnicas y muchos conceptos se fueron informatizando dando lugar a unas interfaces gráficas que disponían de aplicaciones como el procesador de texto, sistemas de archivos, programa de animación, de edición de música y entre otros, también de dibujo y pintura, pero sin olvidarnos de que aún no estaban económicamente al alcance de cualquier usuario. 
Si nos centramos en el origen de los programas digitales de dibujo y pintura, cabe decir que este software inicial funcionaba mediante gráficos en mapa de bits o imagen raster. "un tipo de imagen digital que utiliza pequeños píxeles o elementos de imagen, dispuestos en forma de cuadrícula para representar una imagen"15. Los monitores representaban por entonces una resolución gráfica en píxeles dejando atrás los monitores vectoriales CRT de pantalla verde.

En el marco histórico de los programas de dibujo y pintura, podemos señalar algunos de los que marcaron el origen de este tipo de software basado en mapa de bits que, aunque aún no incluían ningún tipo de herramientas para construir gráficos vectoriales tal y como hoy conocemos, sí fueron precedentes a los medios de representación de la actual gráfica digital.

Alvy Ray Smith (1943), artista, pionero en los gráficos por ordenador y cofundador de los Estudios Pixar, redactó una nota técnica titulada Digital Paint Systems: Historical Overview (Sistemas digitales para pintar: Repaso histórico $)^{16}$ en la cual incorpora una cronología de los sistemas inventados para dibujar y pintar digitalmente y los acontecimientos más importantes acaecidos en los años 70 entre los cuales vamos a destacar:

SuperPaint (1972-73), desarrollado en la Xerox PARC por Richard Shoup, el primer sistema a 8 bits que permitía pintar con pinceles variados y como decía el propio Shoup, "los objetos o áreas de la imagen pueden escalarse en tamaño, más grandes o más pequeños, moverse, copiarse, superponerse, combinarse o cambiarse de color y grabarse en un disco para ser utilizados más adelante o borrarse"17.

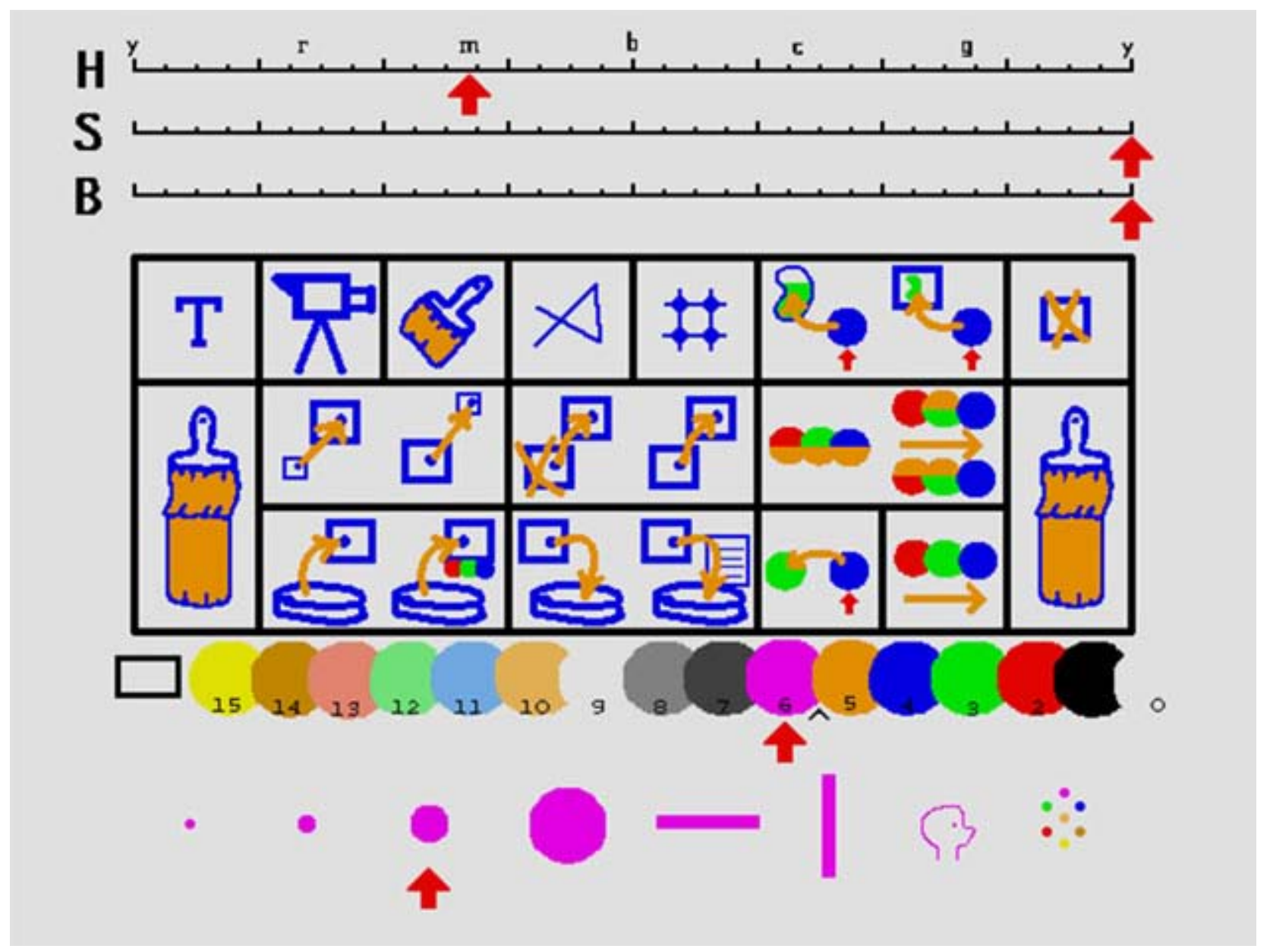

Fig. 11. Menú de herramientas de SuperPaint (1975) diseñado por Richard Shoup. 
Sin embargo, lo más novedoso de este programa era la posibilidad de crear animaciones muy básicas y la de capturar en el framebuffer ${ }^{18}$ del sistema, fotogramas de imagen real mediante una entrada de vídeo estándar y así añadirle cualquiera de las posibilidades que permitían las herramientas de SuperPaint, textos, dibujos, combinarlas con otras imágenes, etc.

In 1973, PARC scientist and visionary, Richard Shoup, changed the worlds of animation and graphic arts forever. He developed the world's first fully-functional frame buffer system, called SuperPaint. It paved the way for digital imaging and much more. A combination of complex hardware and innovative software, SuperPaint digitized video, manipulated images, and allowed animators to create their own computer-generated artwork, and immediately output it to a laser printer or video ${ }^{19}$

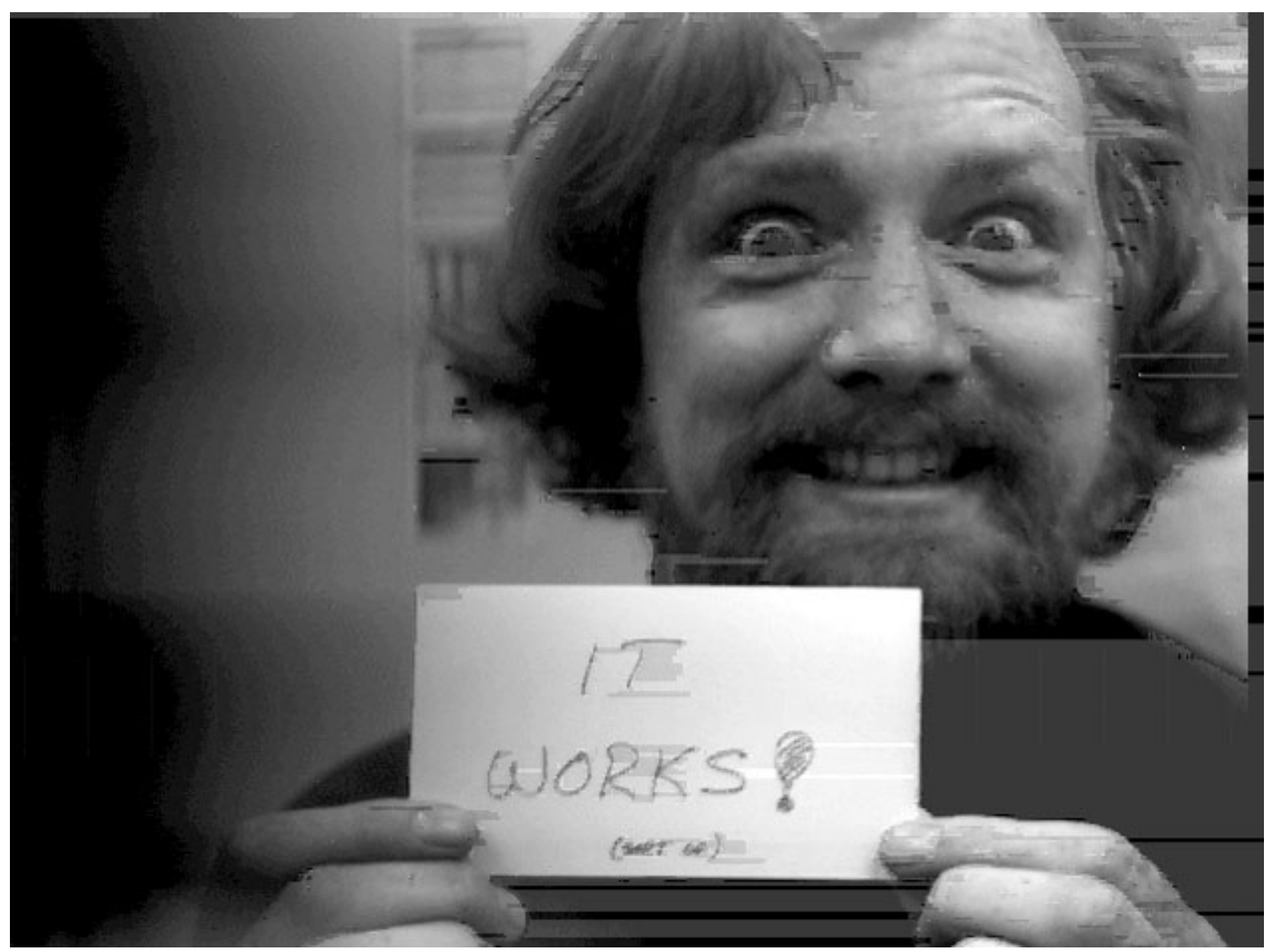

Fig. 12. El cartel dice ¡Funciona!. Richard Shoup en la primera imagen de vídeo capturada por SuperPaint en abril de 1973. El programa permitía digitalizar la señal de vídeo a 8 bits para después poder manipularla y combinarla con otros datos gráficos.

En 1978, SuperPaint fue utilizado por la NASA para reproducir animaciones de la nave espacial Pioneer en su misión por el planeta Venus. En esos tiempos, las naves con esos destinos tan remotos, no llevaban cámara y el artista Damon Rarey (1944-2002) ilustró los experimentos que se llevaron a cabo por su órbita mediante gráficos básicos y animaciones para explicar la complejidad de la misión. 


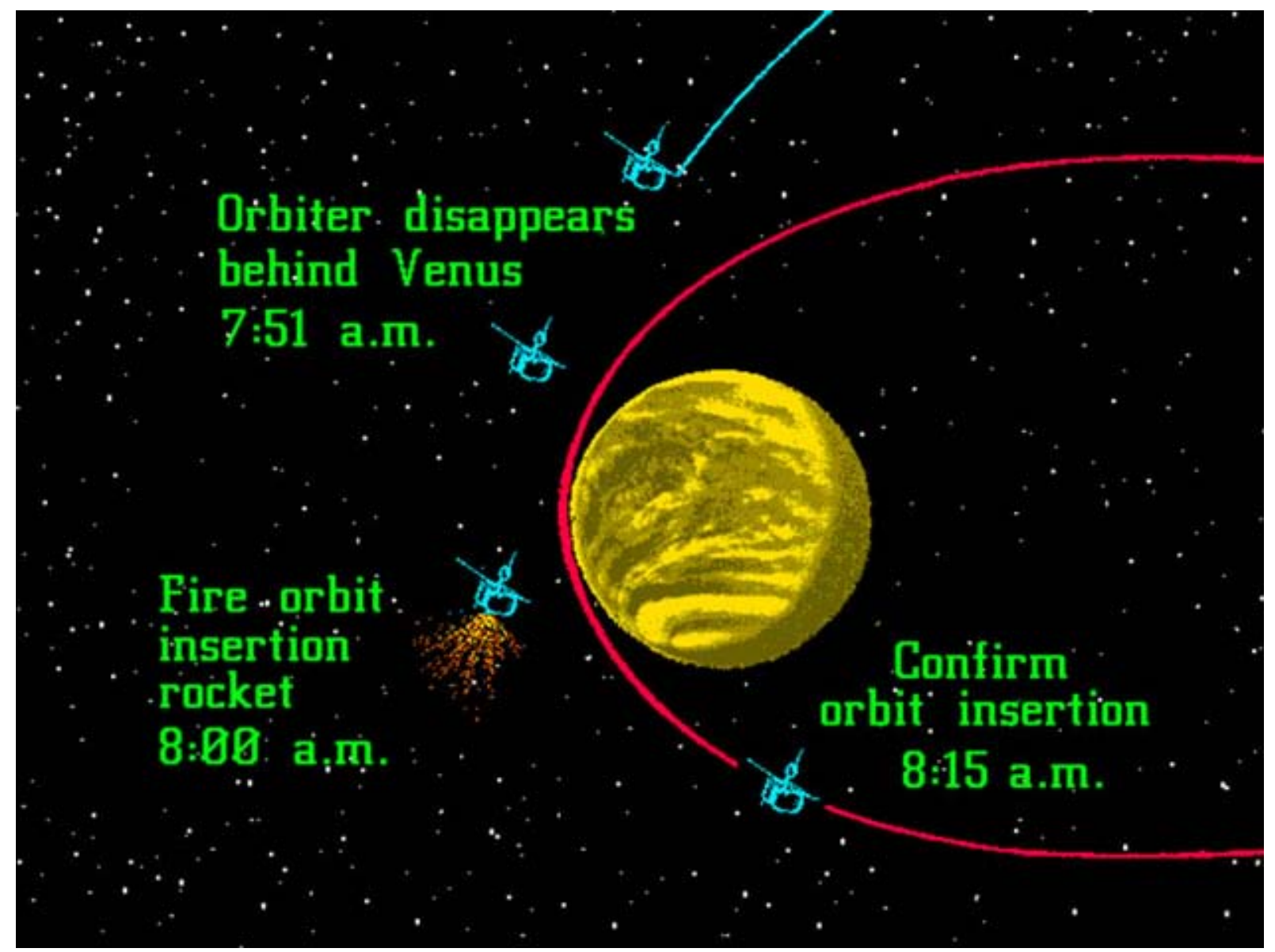

Fig. 13. Presentación de los movimientos de la nave Pioneer realizados con SuperPaint por Damon Rarey en 1978.

James F. Blinn (1949). Científico informático estadounidense que comenzó sus investigaciones en el campo de la representación realista entre los años 1974 y 1977, sus resultados se han convertido en parte de las técnicas estándar de los sistemas de animación de hoy en día como los modelos de iluminación especular, los efectos ambientales, la reflexión de los objetos y el bump mapping ${ }^{20}$ o mapeado topológico.

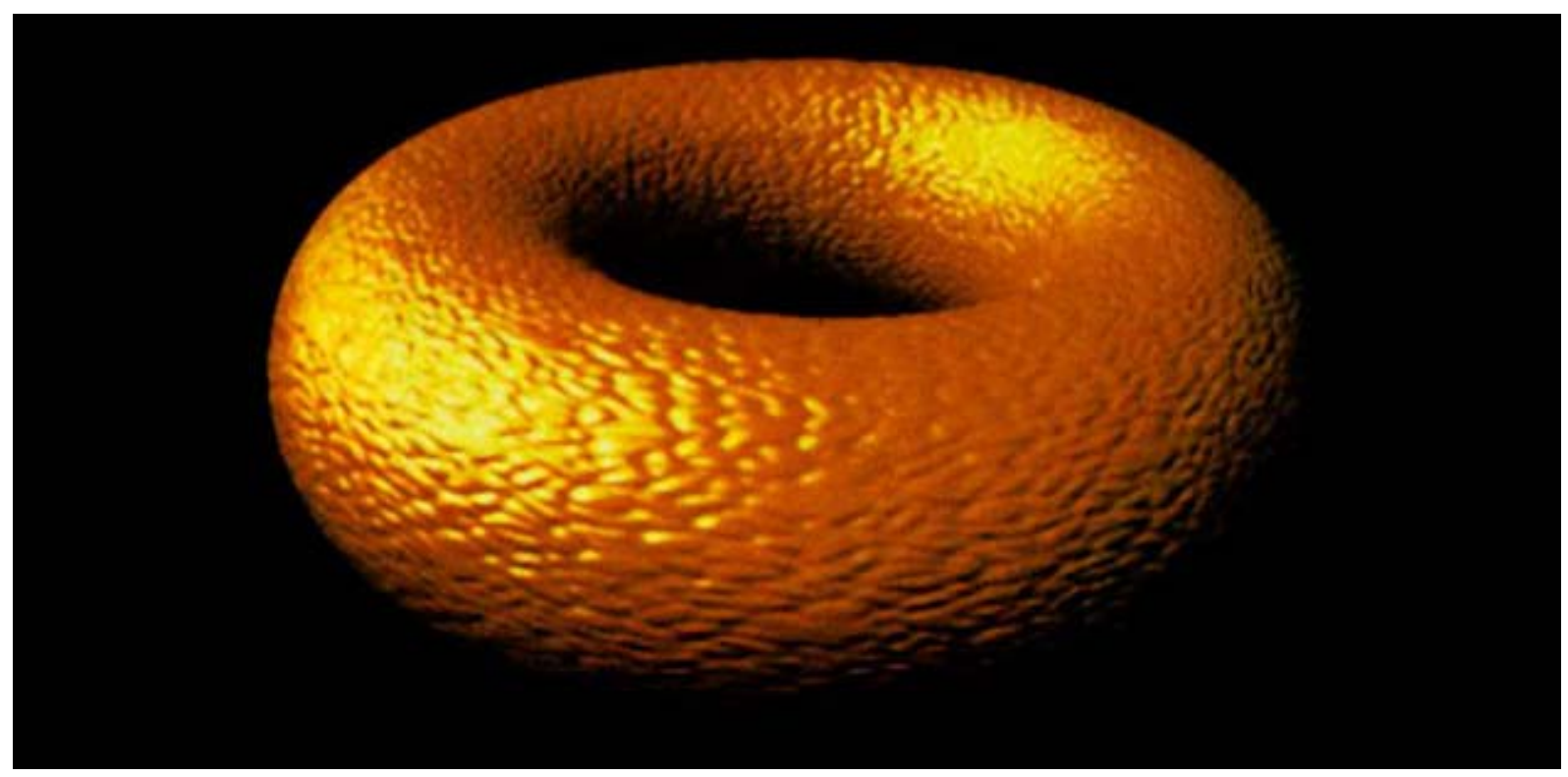

Fig. 14. Demostración de la técnica bump mapping desarrollada por James Blinn en la Universidad de Utah. "Computer Display of Curved Surfaces" University of Utah, 1978. Imagen de SIGGRAPH 78, pp. 286-292. 
BigPaint, Paint y Paint3 (1975-79). Diseñados por Alvy Ray Smith en el Instituto Tecnológico de Nueva York (NYIT). Lo más destacado fue que su versión Paint3 permitía crear gráficos a 24 bits. Fue el primer sistema que disponía de 16,7 millones de colores y además mejoró la manera de definir los colores creando la paleta HSB o HSV (Tono/Saturación/Valor) ${ }^{21}$ como la conocemos hoy en día. Fue desarrollada a su paso por el PARC y presentada en su conferencia en el SIGGRAPH $78^{22}$.

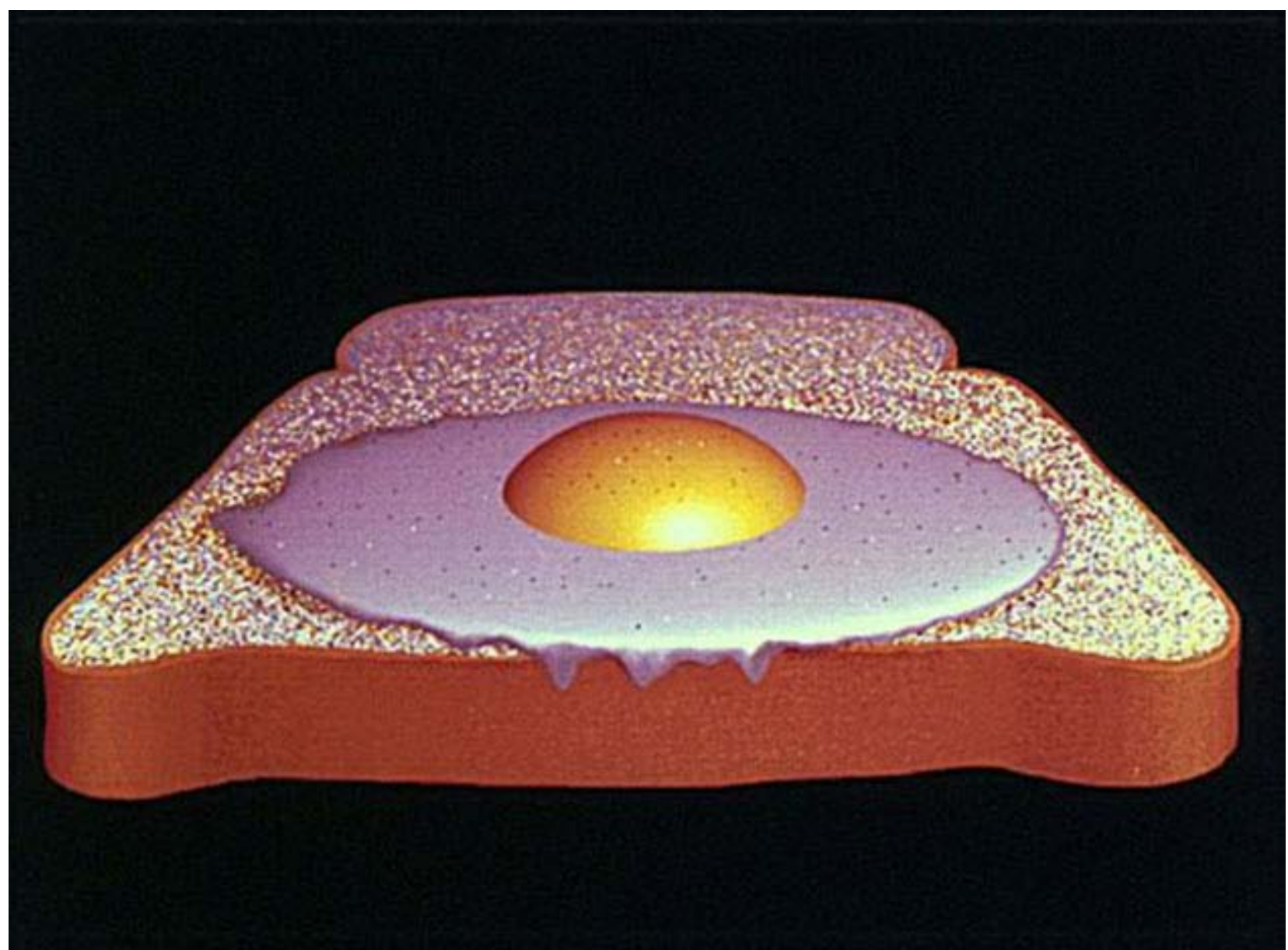

Fig. 15. Egg on Toast. Realizada por Alvy Ray Smith en el NYIT (1977) ${ }^{23}$. Fue La primera imagen digital con una resolución de1024×972 px, el doble de tamaño de las representaciones digitales que hasta entonces eran de $512 \times 486$ px.

Vídeo SunStone creado con Paint (1979). El artista visual americano Ed Emshwhiller (1925-1990) destacó por sus ilustraciones de ciencia ficción y algunas películas digitales experimentales. Junto a Alvy Ray Smith como técnico, produjeron la primera película con efectos 3D con una duración de 3 minutos que ahora es parte del Museo de Arte Moderno de Nueva York. Esta pieza es pionera y clave para la animación por ordenador, fue generada en el Instituto de Tecnología de Nueva York con Paint, este básico programa de pintura digital les permitió crear minuciosas transiciones fotograma a fotograma dando movimiento al color para conseguir la animación en las imágenes estáticas. A primera vista esta película parece un trabajo de software 3D construido con herramientas vectoriales, pero toda su elaboración se realizó con imágenes electrónicas analógicas y las herramientas del software de Paint. 


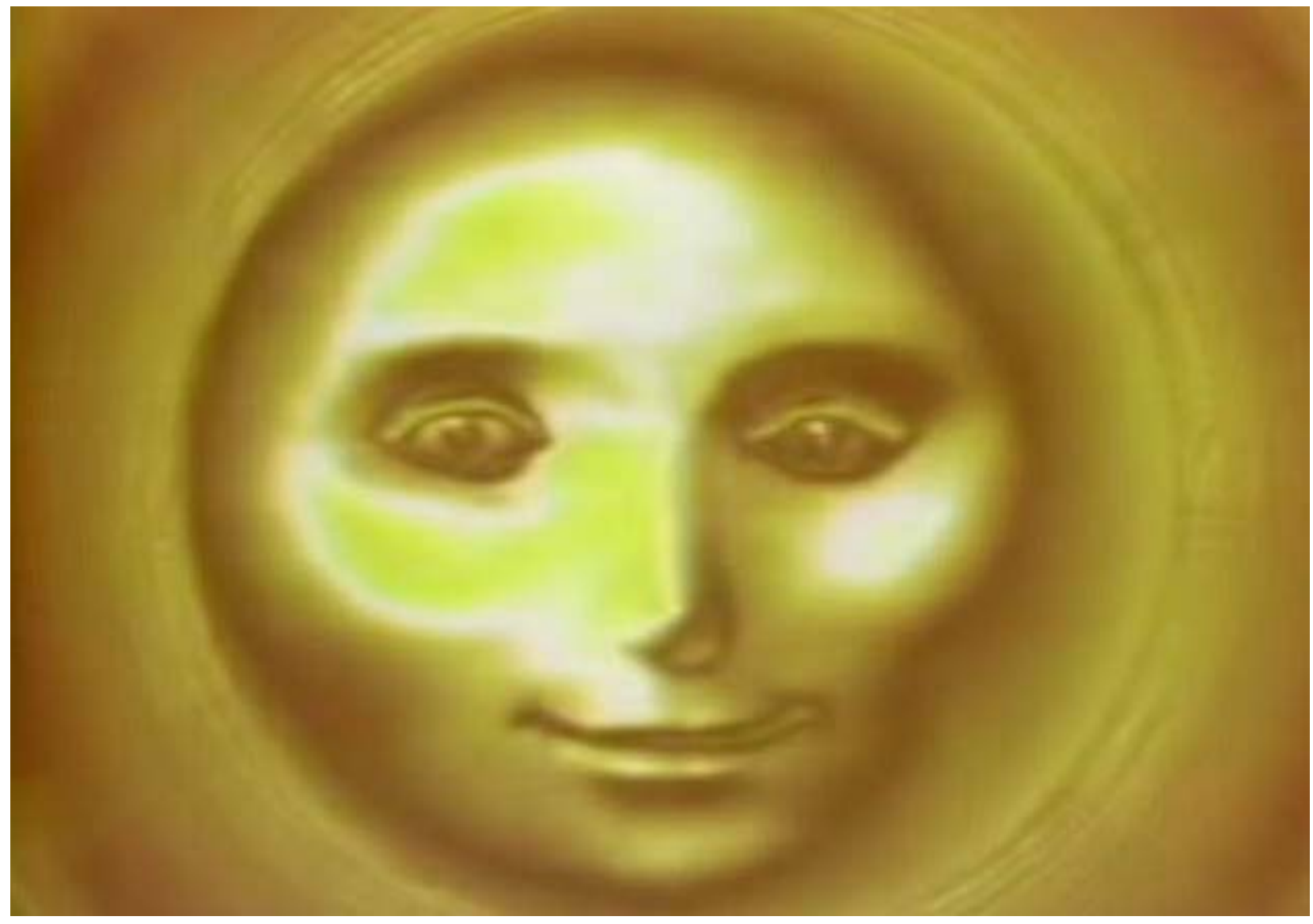

Fig. 16. Egg on Toast. Fotograma de la primera película con efectos 3D realizada por Ed Emswhiller y programada por Alvy Ray Smith en el NYIT para la Fundación Guggengheim (1979) ${ }^{24}$.

Esta breve y selectiva trayectoria histórica que abarca desde los años 50 hasta finales de los 70 , donde surgió el desarrollo de los primeros sistemas y programas gráficos, nos permite rememorar o descubrir los principios metodológicos basados en la tecnología electrónica para el diseño, el dibujo o el modelado tridimensional. Todos estos personajes y sus aportaciones tecnológicas fueron punto de partida a los medios actuales que utilizamos hoy en día de manera casi innata para la comunicación o la creación artística. Una tecnología que rápidamente se ha adentrado en nuestras vidas, pero de la que apenas conocemos sus comienzos y que cada día nos atrapa sin plantearnos ese origen. Este breve tributo histórico es una muestra de admiración y agradecimiento a esos notables y prodigiosos individuos que con sus sutiles y dosificadas aportaciones han abierto un camino a la creatividad facilitando nuevos medios para la expresión artística.

\footnotetext{
*Jerez de la Frontera (Cádiz), 1967. Doctora en Bellas Artes y profesora asociada en la Universidad de Málaga. Comenzó su actividad laboral como intercaladora de dibujos animados e ilustradora infantil. Desde 1994, se ha dedicado a la impartición de cursos como monitora de programas de diseño gráfico, multimedia, retoque fotográfico, diseño web, etc. y dirigidos principalmente a la formación profesional ocupacional, formación continua para trabajadores y teleformación. Diseñadora gráfica habitual del Centro Cívico de la Diputación de Málaga desde 2003 y actualmente combina su docencia e investigación en la Universidad de Málaga con otras actividades de producción gráfica y artística. Email: inmavillagran@uma.es
}

2 EDWARDS, B. "The Never-Before-Told Story of the World's First Computer Art (It's a Sexy Dame)", The Atlantic. 24.01.2013

${ }^{3}$ MANOVICH, L. El software toma el mando, UOCpress, Barcelona 2013, p. 85. 
${ }^{4}$ http://www0.bnl.gov/about/history/firstvideo.php 18.12.2015

${ }^{\mathbf{5}}$ https://www.cl.cam.ac.uk/techreports/UCAM-CL-TR-574.pdf 18.12.2015

6 SUTHERLAND, I. "Sketchpad, a man-machine graphical communication system", Massachusetts Institute of Technology 1963, p. 9. En https://www.cl.cam.ac.uk/techreports/UCAM-CL-TR-574.pdf 18.12.2015

${ }^{7}$ Engelbart bautizó "ratón" a este dispositivo por su similitud con la apariencia de este roedor del que sobresalía un cable por su parte trasera, también se le conoció popularmente con el nombre de "bicho".

${ }^{8}$ Presentación del mouse por Douglas Engelbart en el SRI (1968). https://youtu.be/wfOaEcDilJ8 18.12.2015

${ }^{9}$ https://es.wikipedia.org/wiki/Interfaz_gráfica_de_usuario 22.11.2015

${ }^{10}$ Empresaria e informática que participó en el desarrollo del lenguaje de programación Smalltalk-80 y tuvo varias aportaciones en la programación orientada a objetos. https://es.wikipedia.org/wiki/Adele_Goldberg 12.09.2015

${ }^{11}$ http://hipertextual.com/archivo/2012/03/historia-del-software-smalltalk/ 12.09.2015

${ }^{12}$ INGALLS, DANIEL H.H., Design Principles Behind Smalltalk, BYTE Magazine, The McGraw-Hill Companies, Inc., NY. August 1981, p. 286.

https://archive.org/stream/byte-magazine-1981-08/1981_08_BYTE_06-08_Smalltalk\#page/n299/mode/2up

09.09.2015

${ }^{13}$ KAY, A. / GOLDBERG, A. Personal Dynamic Media, p. 393.

http://www.newmediareader.com/book_samples/nmr-26-kay.pdf 22.11.2015

${ }^{14}$ Ibidem, p. 394.

${ }^{15} \mathrm{http}: / / \mathrm{www}$.britannica.com/topic/raster-graphics 03.06.2015

${ }^{16}$ SMITH, A.R., Digital Paint Systems: Historical Overview (Nota técnica 14 de Microsoft, 30.05.1997). http://alvyray.com/memos/cg/microsoft/14_paint.pdf 23.06.2015

${ }^{17}$ SHOUP, R. "SuperPaint... The Digital Animator", Datamation Magazine, Mayo, 1979, p. 152.

http://www.rgshoup.com/prof/SuperPaint/Datamation.pdf 10.09.2015

${ }^{18}$ Se le llama framebuffer a la sección de memoria usada para almacenar una imagen antes de que aparezca en pantalla. COLLIN, S. Diccionario Multimedia, Mc Graw-Hill, 1996, p. 106.

${ }^{19}$ STEPHENS, D.B. The Money Shot: How Animation Became Profitable. 25.03.2015

https://simplifywork.blogs.xerox.com/2015/03/25/how-animation-became-profitable/\#prettyPhoto 10.01.2016

${ }^{20}$ Técnica de gráficos computacionales 3D creada por James F. Blinn en 1978, permite simular profundidad en una superficie plana alterando la iluminación que recibe dicha superficie. Esto permite lograr más nivel de detalle con menos polígonos. http://dsgp.blogspot.com.es/2005/11/bump-mapping.html 10.01.2016

${ }^{21}$ El modelo HSV fue creado en 1978 por Alvy Ray Smith. Se trata de una transformación no lineal del espacio de color RGB, y se puede usar en las progresiones del color. http://es.encydia.com/pt/HSV 03.09.2015.

${ }^{22}$ SMITH, A.R. Color Gamut transform Pairs. Computer Graphics Lab, NYIT. 1978. http://alvyray.com/Papers/CG/color78.pdf 10.04.2015.

${ }^{23}$ Ilustración publicada en "The Computer Age: A Twenty-Year View", editado por Michael L. Dertouzos y Joel Moses, para ilustrar el artículo de Nicholas Negroponte titulado Return of the Sunday Painter, MIT Press, 1979, p. 33.

${ }^{24}$ https://youtu.be/tMW15OajuKc 02.03.2015.

\section{BIBLIOGRAFÍA}

EDWARDS, B. "The Never-Before-Told Story of the World's First Computer Art (It's a Sexy Dame)", The Atlantic. http://www.theatlantic.com/technology/archive/2013/01/the-never-before-told-story-of-the-worlds-first-computer-artits-a-sexy-dame/267439/24.01.2013

INGALLS, DANIEL H.H., Design Principles Behind Smalltalk, BYTE Magazine, The McGraw-Hill Companies, Inc., NY. August 1981, p. 286.

https://archive.org/stream/byte-magazine-1981-08/1981_08_BYTE_06-08_Smalltalk\#page/n299/mode/2up 09.09.2015

KAY, A. / GOLDBERG, A. Personal Dynamic Media, p. 393. http://www.newmediareader.com/book_samples/nmr-26kay.pdf 15.08.2015 
MANOVICH, L. El software toma el mando, UOCpress, Barcelona 2013, p. 85. SHOUP, R. "SuperPaint... The Digital Animator", Datamation Magazine, Mayo, 1979, p. 152.

http://www.rgshoup.com/prof/SuperPaint/Datamation.pdf 10.09.2015

SMITH, A.R. Color Gamut transform Pairs. Computer Graphics Lab, NYIT. 1978.

http://alvyray.com/Papers/CG/color78.pdf 13.02.2015

SMITH, A.R., Digital Paint Systems: Historical Overview (Nota técnica 14 de Microsoft, 30.05.1997).

http://alvyray.com/memos/cg/microsoft/14_paint.pdf 18.06.2015

STEPHENS, D.B. The Money Shot: How Animation Became Profitable.

https://simplifywork.blogs.xerox.com/2015/03/25/how-animation-became-profitable/\#prettyPhoto 25.03.2015

SUTHERLAND, I. "Sketchpad, a man-machine graphical communication system", Massachusetts Institute of Technology 1963. https://www.cl.cam.ac.uk/techreports/UCAM-CL-TR-574.pdf 24.01.2013

\section{IMÁGENES}

Figura 1. Primera ilustración digital anónima con el motivo de una chica PinUp.

http://www.theatlantic.com/technology/archive/2013/01/the-never-before-told-story-of-the-worlds-first-computer-artits-a-sexy-dame/267439/ 24.01.2013

Figura 2. Captura fotograma de vídeo: https://youtu.be/iGe_brmoopc 09.10.2015

Figura 3. Fotografía de la Faculty of Computer Science and Technology. University of Cambridge. http://www.cl.cam.ac.uk/relics/jpegs/edsac_wilkes.jpg 02.11.2015

Figura 4. William Higinbotham. Autor: Brookhaven National Laboratory. https://www.flickr.com/photos/brookhavenlab/3147769961/ 09.10.2015

Figura 5. Tennis for two. Autor: Brookhaven National Laboratory. https://commons.wikimedia.org/wiki/File:Tennis_For_Two_on_a_DuMont_Lab_Oscilloscope_Type_304-A.jpg 07.09.2015

Figura 6. Ivan Sutherland's Sketchpad system is demonstrated on the console of the TX-2 at MIT (1963). https://design.osu.edu/carlson/history/images/pages/ivan-sutherland_jpg.htm 18.12.2015

Figura 7. Captura de fotogramas del video de demostración del Sketchpad de Ivan Sutherland. https://youtu.be/495nCzxM9PI 18.12.2015

Figura 8. Douglas Engelbart y el mouse. Fotografía: Robert Holmgren https://www.flickr.com/photos/holmgren/ 22.11.2015

Figura 9. A Smalltalk-80 graphical user interface (GUI). Computer History Museum. http://www.computerhistory.org/revolution/input-output/14/347/1859 12.09.2015

Figura 10. Fotogramas del vídeo de presentación del Dynabook (1968). https://youtu.be/hXRhPDoKapM 09.09.2015

Figura 11. SuperPaint (1975) de Richard Shoup. https://www.fxguide.com/featured/alvy-ray-smith-rgba-the-birth-ofcompositing-the-founding-of-pixar/ 10.09.2015

Figura 12. Primera imagen capturada en el registro de SuperPaint de Richard Shoup (1973).

https://simplifywork.blogs.xerox.com/2015/03/25/how-animation-became-profitable/\#prettyPhoto 10.09.2015

Figura 13. Ilustración de Damon Rarey con SuperPaint (1978).

http://www.computerhistory.org/VirtualVisibleStorage/popup_image.php?base_name=102637637 05.01.2016

Figura 14. Técnica BumpMapping desarrollada por Jim Blinn (1978). http://www.jimblinn.com/publications/ 10.01.2016

Figura 15. Ilustración de Alvy Ray creada con BigPaint (1977). http://alvyray.com/art/EggOnToast.htm 03.09.2015

Figura 16. Captura de fotograma del vídeo SunStone de Ed Emswhiller y Alvy Ray Smith (1979).

https://youtu.be/tMW15OajuKc 03.09.2015

Revista internacional de investigación, innovación y desarrollo en Diseño • ISSN 1889-433 x 